
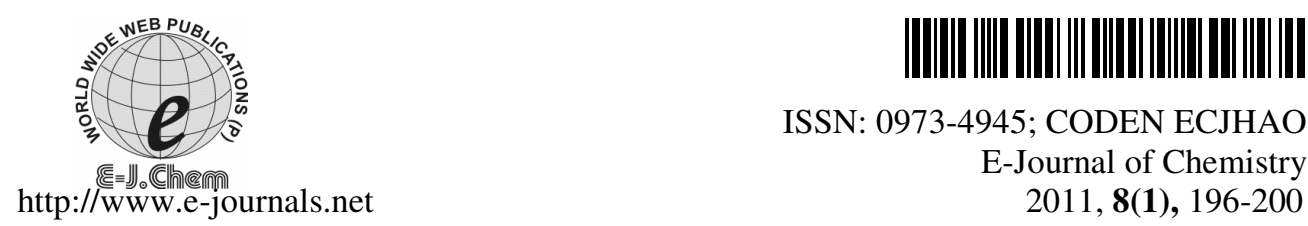

ISSN: 0973-4945; CODEN ECJHAO

E-Journal of Chemistry 2011, 8(1), 196-200

\title{
Synthesis and Characterization of Nanoporous Carbon Materials; The Effect of Surfactant Concentrations and Salts
}

\author{
SHOKOOFEH GERANMAYEH, ALIREZA ABBASI* and ALIREZA BADIEI
}

\author{
School of Chemistry \\ College of Science, University of Tehran, Tehran, Iran \\ aabbasi@khayam.ut.ac.ir
}

Received 22 January 2010; Revised 27 May 2010; Accepted 17 July 2010

\begin{abstract}
Nanoporous carbon framework was synthesized using phenol and formaldehyde as carbon precursors and triblock copolymer (pluronic F127) as soft template via evaporation induced self-assembly. Hexagonal mesoporous carbon with specific surface area of $350 \mathrm{~m}^{2} / \mathrm{g}$ through optimizing the situation was obtained. The effects of different surfactant/phenol molar ratio and presence of salts on specific surface area, pore size and pore volume for all the prepared samples were studied by means of the Brunauer-Emmett-Teller (BET) formalism, powder X-ray diffraction technique and FT-IR spectroscopy.
\end{abstract}

Keywords: Nanoporous carbon materials, Self-assembly, Triblock copolymer, Specific surface area

\section{Introduction}

Porous carbon materials have attracted great interest due to their high surface area, large pore volume, chemical inertness and electrical conducting properties ${ }^{1}$. These nanostructure materials are found to be important in many fields such as separation, adsorption, catalysts and catalyst supports in catalytic processes ${ }^{2-6}$.

Many advances in carbon technology are related to improvement of existing fabrication methods and the development of new synthetic techniques ${ }^{7-9}$. Recently, various types of ordered nanoporous carbons have been reported via a multi-step synthetic procedure, in which amphiphilic surfactants or block copolymers are employed as soft templates. Using amphiphilic surfactants or block copolymer self-assembly, provides routes to a range of materials with diverse multi-component structures of atoms, ions and molecules, held together by weak non-covalent interactions which can drive inorganic-organic and organicorganic assembly to form inorganic and organic frameworks, respectively ${ }^{10}$. 
Highly ordered mesoporous carbon materials using soft templates were synthesized in $2004^{11}$. Zhao and co-workers prepared a variety of ordered mesoporous carbons, "C-FDU-15 and C-FDU-16" with hexagonal (p6m) and cubic $(\operatorname{Im} 3 \mathrm{~m})$ structures using phenol/formaldehyde as the carbon precursor and F127 and P123 block copolymers as the soft templates ${ }^{12}$. The interaction between both organic precursors and templates and the organic precursors themselves should be considered in an organic-organic assembly for preparing ordered mesoporous polymers and carbons with diversified structures, especially for the common strategies such as hydrothermal treatment ${ }^{13,14}$, or the solvent evaporation induced selfassembly (EISA) method ${ }^{15,16}$.

Here we report the synthesis of ordered mesoporous carbon structure via the organicorganic self-assembly. The pore size and pore structure of the prepared mesoporous carbons have been studied, using different compositions of the triblock polymer.

\section{Experimental}

All chemicals were purchased from Merck Company and used as received without any further purification.

\section{Preparation of resol precursors}

Resol, a low-molecular-weight and soluble phenolic resin, was prepared from phenol and formaldehyde in a base-catalyzed process. Firstly, phenol $(6.1 \mathrm{~g}, 65.0 \mathrm{mmol})$ was melted at $40-42{ }^{\circ} \mathrm{C}$ in a flask, followed by adding aqueous sodium hydroxide solution $(1.3 \mathrm{~g}, 6.5 \mathrm{mmol})$ under stirring. After $10 \mathrm{~min}$ stirring, formalin $(37 \mathrm{wt} \%, 10.5 \mathrm{~g}$ ) containing formaldehyde (130 mmol) was added drop wise keeping temperature $50{ }^{\circ} \mathrm{C}$. Afterward the mixture was heated at $70-75{ }^{\circ} \mathrm{C}$ and stirred for $1 \mathrm{~h}$ more, and then the mixture was cooled to ambient temperature. The $\mathrm{pH}$ was adjusted to neutral $(\sim 7.0)$ by $\mathrm{HCl}(0.6 \mathrm{M})$ solution and water was removed by rotary evaporator at $45{ }^{\circ} \mathrm{C}$. Ethanol was added to the final product; thereby sodium chloride precipitates. The molar ratio of phenol/formaldehyde/ $\mathrm{NaOH}$ was 1:2:0.1.

\section{Synthesis of mesoporous polymers and carbons}

Samples were synthesized by a solvent evaporation induced self-assembly method with copolymers F127 as a template in an ethanol solution. Molar ratios of all samples (1-4) are depicted in Table 1. In a typical preparation, F127 (10.0 g) was dissolved in ethanol (200.0 g). Then resol (50.0 g) precursors in ethanol solution containing phenol $(6.1 \mathrm{~g}, 65.0 \mathrm{mmol})$ and formaldehyde $(3.9 \mathrm{~g}, 130.0 \mathrm{mmol})$ was added. For all samples except 1, resol solution was added by removing sodium chloride precipitates. After stirring for $10 \mathrm{~min}$, a homogeneous solution was obtained. The solution was poured into dishes to evaporate ethanol at room temperature for $12-16 \mathrm{~h}$, followed by heating in an oven at $100{ }^{\circ} \mathrm{C}$ for $24 \mathrm{~h}$ in order to thermopolymerize the phenolic resins. The as-made products, transparent films, were scraped from the dishes and crushed into powders. Calcination was carried out in a tubular furnace under an argon atmosphere with a flow rate of $\sim 90 \mathrm{~cm}^{3} / \mathrm{min}$ at $350{ }^{\circ} \mathrm{C}$ for $5 \mathrm{~h}$ with a temperature increase rate of $1{ }^{\circ} \mathrm{C} \mathrm{min}^{-1}$ to obtain porosity and decomposition of amphiphilic triblock copolymer template.

Mesoporous carbon materials was prepared by direct transformation of the corresponding mesostructured polymers by carbonization under argon. Carbonization was carried out at $900{ }^{\circ} \mathrm{C}$ for $5 \mathrm{~h}$. The temperature was increased at a rate of about $1{ }^{\circ} \mathrm{C} \mathrm{min}{ }^{-1}$ and held at 200,350 and $500{ }^{\circ} \mathrm{C}$ for $2 \mathrm{~h}$ before reaching the final temperature. The synthetic conditions in different samples were summarized in Table 1 . 
Table 1. Synthetic conditions and molar ratio for different samples. The molar ratios for the phenol $(65.0 \mathrm{mmol})$, formaldehyde $(130.0 \mathrm{mmol})$ and $\mathrm{NaOH}(6.5 \mathrm{mmol})$ by keeping the same in all samples while the ratios of F127 are different

\begin{tabular}{ccc}
\hline Sample & Molar ratio F127 & NaCl \\
\hline 1 & 0.012 & Unfiltered \\
2 & 0.012 & Filtered \\
3 & 0.010 & Filtered \\
4 & 0.015 & Filtered \\
\hline
\end{tabular}

\section{Measurements}

The ordered structure of all samples were recorded on a XPert MPD diffractometer by using $\mathrm{Cu}$ k $\alpha$ radiation $(40 \mathrm{KV}, 40 \mathrm{~mA})$. Nitrogen adsorption/desorption isotherms were measured using a Belsorp-Mini instrument at $77 \mathrm{~K}$ (all the samples were prior degassed in vacuum at $200{ }^{\circ} \mathrm{C}$ for at least $6 \mathrm{~h}$ ). Fourier transform infrared (FT-IR) spectra were collected on Bruker Equinox 55 spectrophotometer.

\section{Results and Discussion}

Samples $\mathbf{1}$ and $\mathbf{2}$ were synthesized with the same molar ratio of surfactant / phenol (Table 1). The $\mathrm{NaCl}$ salt obtained in the preparation of resol precursor process was filtered in $\mathbf{2}$, while in 1 was left unfiltered.

The XRD pattern of 2 shows a reflection peak at $2 \theta$ of 1.03 with d-spacing of $8.10 \mathrm{~nm}$ but this pattern for $\mathbf{1}$ doesn't show any intensive peak at low angle, which indicates that presence of salt, can decrease the symmetry (Figure 1).

Although the amount of sodium chloride is not that much to observe sharp peaks, the $\mathrm{XRD}$ at higher angles for $\mathbf{1}$ confirm the presence of sodium chloride in final product (Figure 2).

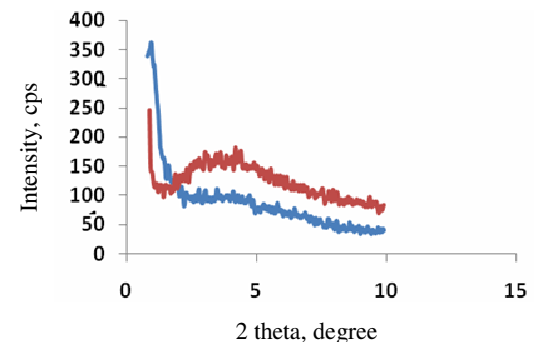

Figure 1. XRD pattern of $1 \& 2$ at low angles

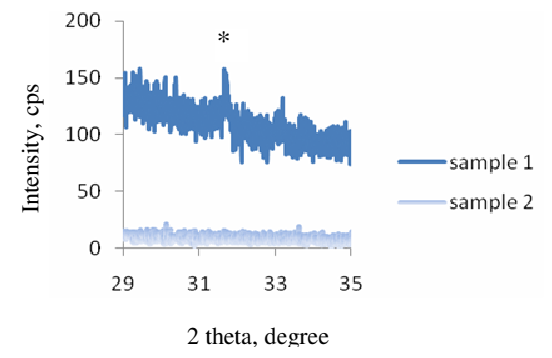

Figure 2. XRD pattern of $1 \& 2$ at high angles confirming the presence of sodium chloride, the characterized observed peak of $\mathrm{NaCl}$ marked by *

$\mathrm{N}_{2}$ adsorptions of all samples are shown in Figure 3. Sample 2 shows a BET surface area of $307 \mathrm{~m}^{2} \mathrm{~g}^{-1}$, a total pore volume of $0.18 \mathrm{~cm}^{3} \mathrm{~g}^{-1}$ and an average pore diameter of 2.37 $\mathrm{nm}$ (Figure 3).

XRD pattern of all samples with different molar ratio are shown in Figure 4. The XRD pattern of 3 shows 3 resolved diffraction peaks. They can be indexed to (10), (20), (21) planes with d-spacing of $8.98,7.91,5.04 \mathrm{~nm}$, respectively, associated with the hexagonal symmetry. A strong reflection peak at $2 \theta$ of 0.98 indicates that the sample has a degree of an ordered mesostructure ${ }^{14}$. This sample has a BET surface area of $350 \mathrm{~m}^{2} \mathrm{~g}^{-1}$ and a total pore volume of $0.20 \mathrm{~cm}^{3} \mathrm{~g}^{-1}$ and an average pore diameter of $2.30 \mathrm{~nm}$. 


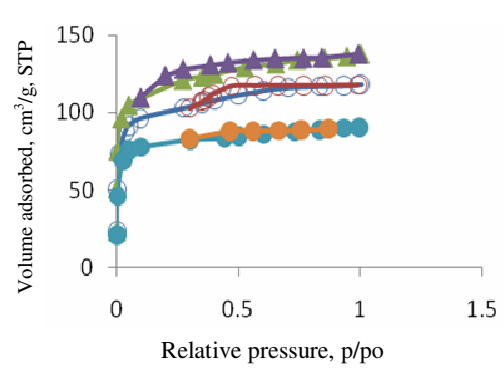

Figure 3. $\mathrm{N}_{2}$ adsorption-desorption isotherms of samples $\mathbf{2}$ (open circles, middle), $\mathbf{3}$ (solid triangles, top) and $\mathbf{4}$ (solid circles, down)

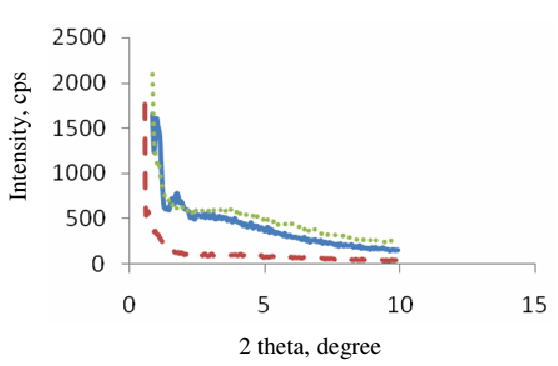

Figure 4. Low angle XRD pattern of $\mathbf{2}$ (dash line), 3 (solid line) and $\mathbf{4}$ (dot) with different molar ratio composition

Sample 4 was prepared by increasing the F127/Phenol molar ratio. XRD pattern of this sample show 1 diffraction peak. This approximately intensive peak indicates that the sample, to some extent, has an ordered meso-structure.

The BET surface area of $242 \mathrm{~m}^{2} \mathrm{~g}^{-1}$, the total pore volume of $0.12 \mathrm{~cm}^{3} \mathrm{~g}^{-1}$ and an average pore diameter of $1.92 \mathrm{~nm}$, are all calculated from the $\mathrm{N}_{2}$ adsorption isotherms. The textural properties of all samples are summerized in Table 2.

Table 2. Textural properties of mesoporous carbon

\begin{tabular}{cccccc}
\hline $\begin{array}{c}\text { Sample } \\
\text { name }\end{array}$ & $\begin{array}{c}d \text {-spacing, } \\
\mathrm{nm}\end{array}$ & $\begin{array}{c}\text { Surface } \\
\mathrm{area}^{\mathrm{a}}, \mathrm{m}^{2} / \mathrm{g}\end{array}$ & $\begin{array}{c}\text { Pore volume }^{\mathrm{b}}, \\
\mathrm{cm}^{3} / \mathrm{g}\end{array}$ & $\begin{array}{c}\text { Pore size } \\
\mathrm{nm}\end{array}$ & $\begin{array}{c}\text { Pore wall } \\
\text { thickness }^{\mathrm{d}}, \mathrm{nm}\end{array}$ \\
\hline $\mathbf{1}$ & - & 36 & 0.01 & 1.77 & - \\
$\mathbf{2}$ & 8.51 & 307 & 0.18 & 2.37 & 7.4 \\
$\mathbf{3}$ & 8.98 & 350 & 0.20 & 2.30 & 6.2 \\
$\mathbf{4}$ & 8.10 & 242 & 0.12 & 1.92 & 7.4 \\
\hline
\end{tabular}

${ }^{a}$ Brunauer- Emmett- Teller (BET) surface area. ${ }^{b}$ Pore volume calculated as the amount of nitrogen adsorbed at a relative pressure of 0.99. ${ }^{c}$ Pore diameter calculated by the Barrett-Joyner-Halenda (BJH) method using adsorption branches.

${ }^{d}$ Pore wall thickness calculated by the formula ${ }^{w=\frac{2}{\sqrt{3}} d-D}$, where $d$ represents $d$-spacing and $D$ represents the BJH pore diameter

All samples except 1 show similar FT-IR spectra. Before calcinations at $350{ }^{\circ} \mathrm{C}$ they show a broad band at $\sim 3500 \mathrm{~cm}^{-1}$ that can be assigned to $-\mathrm{OH}$ stretching, suggesting the existence of a large amount of phenolic -OH group and un-cross-linked benzyl alcohol. Band at $\sim 2800 \mathrm{~cm}^{-1}$ arises from C-O and C-H stretching of F127. After calcination at $900{ }^{\circ} \mathrm{C}$ the FT-IR vibration bands disappear, which indicates that the framework constitutions have been changed.

\section{Conclusion}

Mesoporous carbon materials were synthesized through surfactant self-assembly. The pore size and pore volume of the mesoporous carbons were affected by different composition of surfactants. By increasing the molar ratio of triblock copolymers as soft templates, the pore size and consequently the pore volume and pore wall thickness decrease, resulting the structural symmetry to decrease, as well. Furthermore it was shown that the presence of salt can decrease the porosity in carbon products. The salt particles may fill the pores and thus prevent porosity in the sample. 


\section{Acknowledgment}

This research was supported by the Research Council of the University of Tehran.

\section{References}

1 Jin J, Nishiyama N, Egashira Y and Ueyama K, Micropor Mesopor Mater., 2009, 118(1-3), 218-223.

2 Xing R, Liu N, Liu Y, Wu H, Jiang Y, Chen L, He M and Wu P, Adv Funct Mater., 2007, 17, 2455.

3 Jenekhe S A and Chen X L, Science, 1999, 283, 372.

4 Johnson S A, Ollivier P J and Mallouk T E, Science, 1999, 283, 963-965.

5 Peters E C, Svec F and Frechet J M J, Adv Mater., 1999, 11, 1169-1181.

6 Deng H, Gin D L and Smith R C, J Am Chem Soc., 1998, 120, 3522.

7 Liang C, Li Z and Dai S, Angew Chem Int Ed., 2008, 47, 3696-3717.

8 Bansal R C, Donnet J B and Stoeckli F, Active Carbone, Marcel Dekker, New York, 1998.

9 Yang R T, Adsorbents: Fundamentals and Applications, Wiley Interscience, New York, 2003.

10 Meng Y, Gu D, Zhang F, Shi Y F, Cheng L and Feng D, Wu Z X, Chen Z X, Wan Y, Stein A, Zhao D Y, Chem Mater., 2006, 18(8), 4447-4464.

11 Liang C D, Hong K L, Guiochon G A, Mays J W and Dai S, Angew Chem Int Ed., 2004, 43, 5785-5789.

12 Meng Y, Gu D, Zhang F, Shi Y, Yang H and Li Z, Yu C, Tu B and Zhao D Y, Angew Chem Int Ed., 2005, 44, 7053.

13 Beck J S, Vartuli J C, Roth W J, Leonowicz M E, Kresge C T and Schmitt K D, J Am Chem Soc., 1992, 114, 10834.

14 Zhao D Y, Feng J L, Huo Q S, Melosh N, Fredrickson G H, Chmelka B F and Stucky G D, Science, 1998, 279, 548-552.

15 Brinker C J, Lu Y F, Sellinger A and Fan H Y, Adv Mater, 1999, 11, 579-585.

16 Soler-Illia GJDA, Crepaldi E L, Grosso D and Sanchez C, Curr Opin Colloid Interface Sci., 2003, 8, 109-126. 


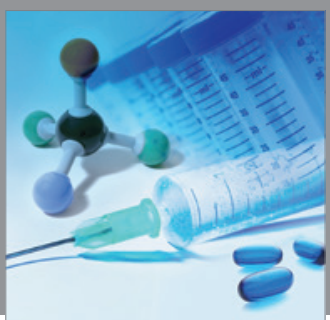

International Journal of

Medicinal Chemistry

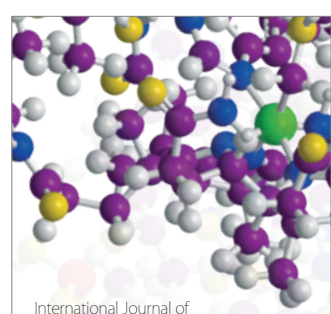

Carbohydrate Chemistry

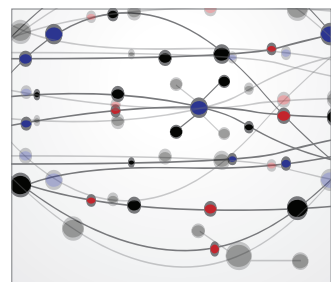

The Scientific World Journal
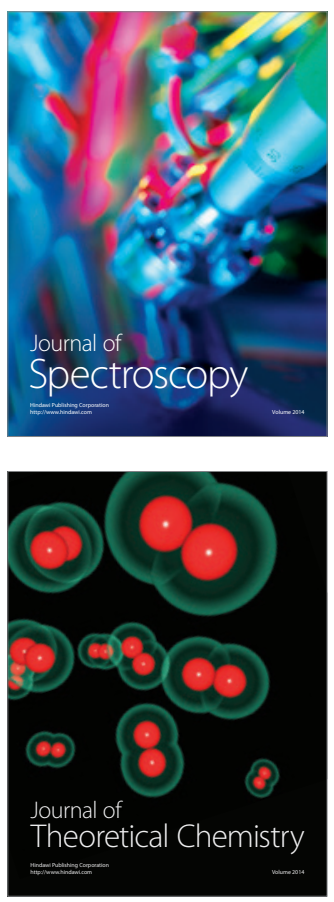
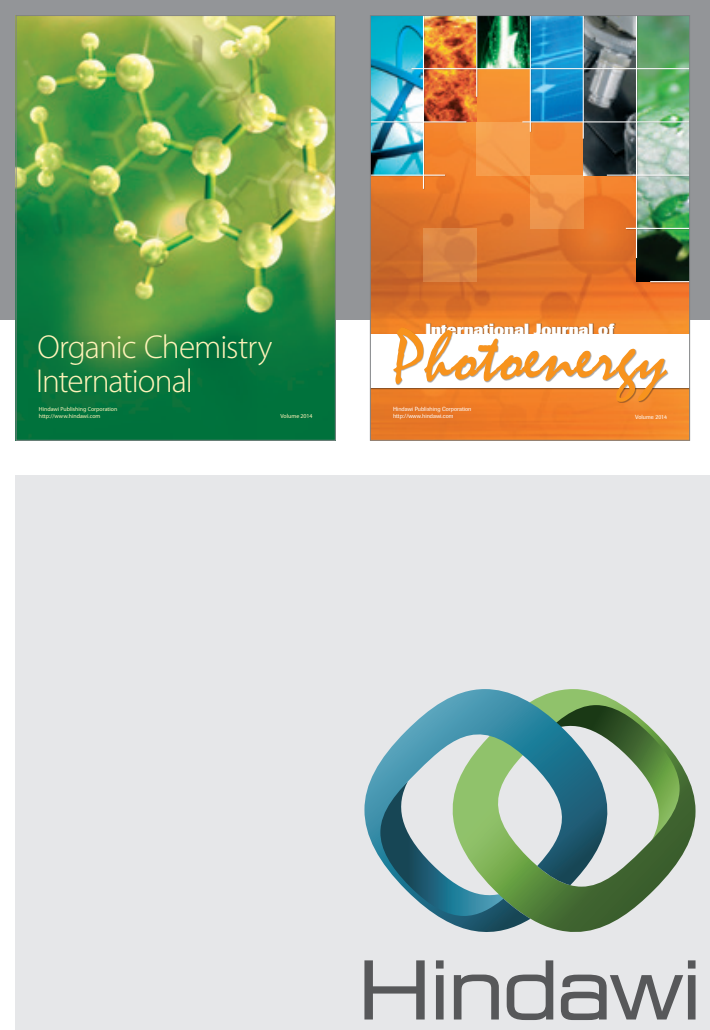

Submit your manuscripts at

http://www.hindawi.com
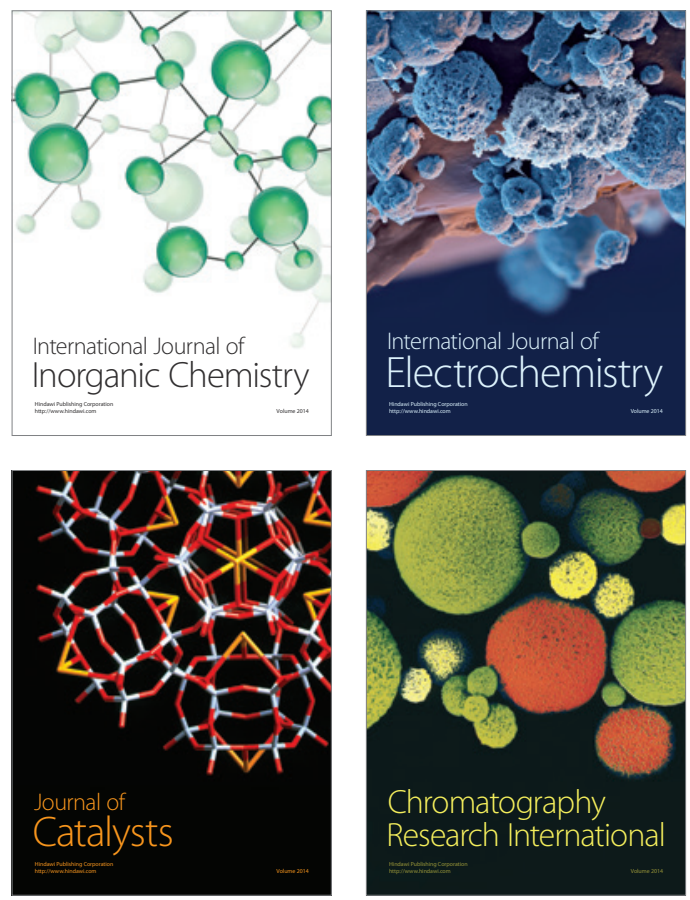
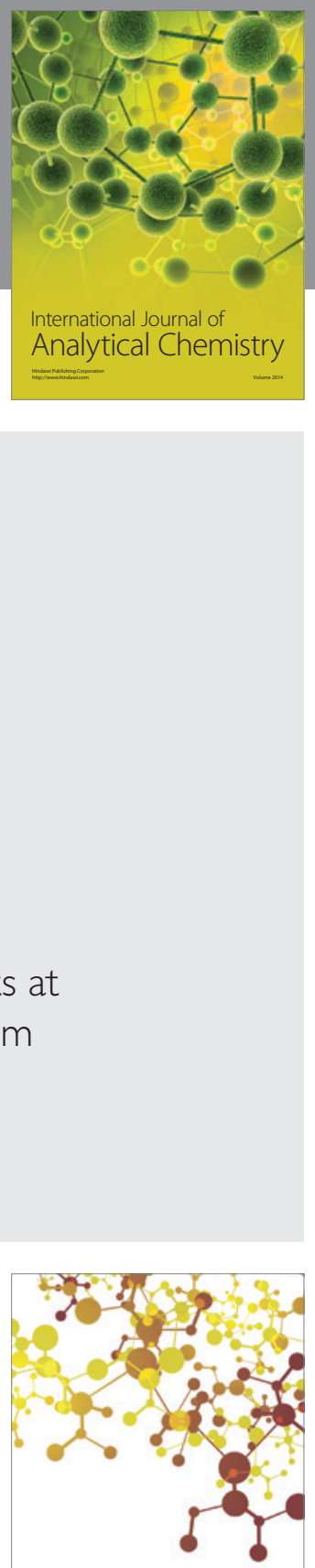

Journal of

Applied Chemistry
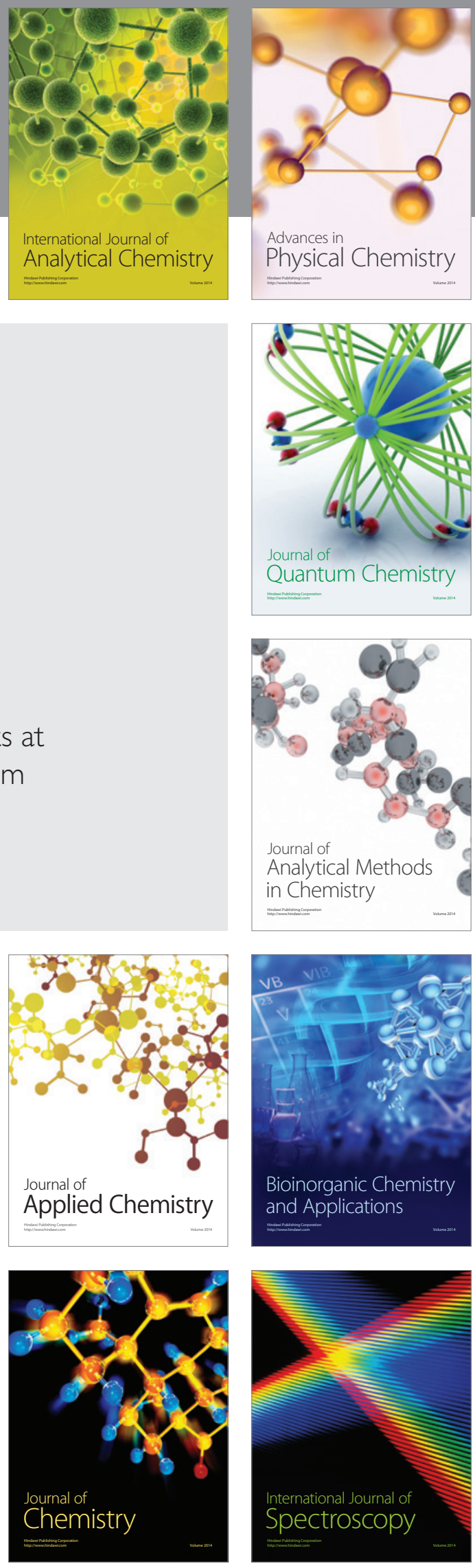